\title{
LA CIENCIA FICCIÓN EN AMÉRICA LATINA. APROXIMACIONES TEÓRICAS AL IMAGINARIO DE LA EXPERIMENTACIÓN CULTURAL
}

POR

\author{
Silvia Kurlat Ares
}

Cuando hace cinco años llamamos a la publicación de un volumen sobre la ciencia ficción en América Latina, era nuestra voluntad ofrecer un espacio inicial de debate para un área de trabajo que la crítica académica en español raras veces había visitado, aunque no así la ensayística del fandom o de los propios productores de la modalidad. Los trabajos que llegaron entonces, sin cubrir (ni pretender agotar) todo el espectro de la producción ni todos los eventuales enfoques críticos, intentaban ofrecer un muestreo de las múltiples opciones que la ciencia ficción propone como espacio de reflexión. El inusual interés y la muy positiva acogida del volumen LXXVIII de la Revista Iberoamericana dedicado a este tema, hablan a las claras del franco desarrollo de este campo de investigación y de las posibilidades que ofrece. En este sentido, los últimos años han visto un marcado incremento de publicaciones de volúmenes con un fuerte enfoque en los aspectos teóricos de la ciencia ficción de América Latina, incluyendo la producción en español y en portugués (Brown; Cornejo Córdoba; Ginway y Brown) así como en la edición de revistas académicas dedicadas al tema en forma exclusiva (tal el caso de Alambique) y en la celebración de congresos internacionales (como el de Berlín 2013, el amplio espacio del track académico de LONCON 3 dedicado a América Latina, y Puerto Rico 2015).

Si el volumen del año 2012 resultó exitoso, no lo fue sólo o simplemente por la calidad de los trabajos allí reunidos. El volumen vino a insertarse en un creciente diálogo en torno al lugar de la ciencia ficción en el campo cultural. Pero además apuntaba a señalizar una serie de indagaciones en torno al espacio del conocimiento y de la producción de saberes y su impacto en diversos ámbitos, la existencia de tensiones entre misticismo, superstición y racionalidad, y también una preocupación por el desarrollo de los proyectos de estados nacionales y su relación con la cultura. Los trabajos de ese primer volumen abrieron un sucinto temario en torno a las operaciones de la ciencia ficción, sumándolo a la constante preocupación por organizar corpora textuales y establecer cronologías que permitieran modelar y afinar la investigación, 
es decir, presentar una suerte de estado de la cuestión más allá de lo que Ginway y Brown han llamado la fase "arqueológica" de la investigación (Ginway y Brown 2). El volumen permitió atisbar los diálogos de la ciencia ficción con sus campos culturales locales, con la producción internacional tanto de la ciencia ficción como de otras literaturas y, al mismo tiempo, con otras formas de producción cultural, y con distintos discursos y saberes.

En el complejo espacio de reflexión que parece haber estallado desde el inicio de nuestro diálogo, esas claves nos resultan ahora apenas suficientes. En este sentido, el presente volumen quiere ampliar la discusión planteada hace cinco años, con una aproximación a las principales preguntas teóricas que han surgido en los debates acerca de la ciencia ficción producida en América Latina en diferentes ámbitos, tanto en EE.UU., como en Europa y en la propia región. Si bien no intentamos aquí hacer un mapa completo de problemáticas, sí queremos proponer prácticas de análisis que se alejen de lo que se ha descripto como estudios que apuntan a establecer los parámetros de legitimidad del campo sin necesariamente detenerse en el análisis (Ginway y Brown 7). Si tal ejercicio ha sido necesario, también ha sido incompleto. En este sentido, el trabajo de Rosso que abre el presente volumen es una meditación sobre la construcción de las historias nacionales de la ciencia ficción y una indagación sobre en qué medida tales historias permiten ver una tensión entre los modos de entender la relación entre el megatexto que llamamos "ciencia ficción" y los corpora literarios nacionales. Dentro de esta misma línea, los trabajos de Espinosa y de Maguire sobre la ciencia ficción colombiana y puertorriqueña respectivamente, organizan sus lecturas en el cruce entre los diversos proyectos de estado, los imperativos de la modernidad y la crítica del rol de los letrados dentro de esos planes. Si bien son miradas que construyen genealógicamente sus objetos, también analizan cuidadosamente cuáles son las operaciones que constituyen a la ciencia ficción como modalidad dentro de sus respectivos campos y en qué medida los mismos se recortan y separan de otras formas discursivas. Esa preocupación también aparece en cómo la ciencia ficción establece sus diálogos con el resto de su propio campo cultural. Estos no son textos que hablen en el vacío pues el megatexto de la ciencia ficción tiene eslabones en múltiples direcciones. Así, los artículos de Cano, Rivero y Pórben reflexionan sobre cuáles son esas relaciones no sólo en el ámbito de lo social y de lo político, sino en el espacio de narrativas que operan a partir de diferencias programáticas fuertes.

Es bien sabido que la ciencia ficción resiste definiciones fáciles, al punto que en algún lugar Samuel Delany ha dicho que la ciencia ficción tiene el mismo estatus ontológico que un unicornio. De allí que definirla como un género sea problemático y que muchos de sus cultores prefieran hablar de una modalidad de producción y de lectura. Las definiciones formalistas, las estructuralistas, e incluso las historiográficas muchas veces acaban o bien por limitar su propio objeto de estudio o bien por reducirlo a un objeto inmanejable dentro de los entramados de la cultura popular. Aun esta última 
aproximación es problemática, ya que cabría preguntarse en qué consiste un fenómeno popular (e incluso de masas) que es mayormente consumido por públicos educados, con altos porcentajes de receptores universitarios en sus rangos, y cuya repercusión, fuera de algunos contados productos, tiene un alcance y una distribución cercanos a lo artesanal. Dentro de este marco pueden ubicarse trabajos como el de Honores que indaga sobre la evolución de la historieta de ciencia ficción en Perú o el de Miguel García sobre la evolución del cine mexicano de ciencia ficción.

En el caso de América Latina, las dificultades en el análisis son quizás mayores que en otros lugares, no sólo por la desconfianza de la crítica académica hacia la modalidad, o por la dificultad en acceder a los materiales, o por la falta de canales para hacer efectiva la circulación y recepción de los artefactos de la ciencia ficción. La importancia hegemónica que asumen tanto la literatura fantástica como el realismo mágico como instrumentos de análisis vino a desestabilizar el modo en que se percibieron los objetos de una ciencia ficción cuyos bordes inestables nunca permitieron que se adscribiera a fáciles categorizaciones. Esa inestabilidad puede observarse, en parte, en cierta falta de consenso analítico a la hora de utilizar vocabularios por parte del conjunto de los críticos: hasta dónde la ciencia ficción es un género o una modalidad, cuál es el límite que la separa de lo fantástico, y cómo entender los universos visuales y narrativos que genera a partir de esas (in)definiciones no son una parte menor de los debates. Esas fluctuaciones aparecen en los trabajos aquí reunidos, pero recorren el campo entero, en especial en América Latina, donde buena parte de la producción de la ciencia ficción no se adscribe a las definiciones que engloban y describen la modalidad en otras latitudes. De hecho, esas variaciones pueden verse en toda suerte de discusiones tanto en revistas y libros de crítica especializada, como en las redes virtuales, o en los pasillos de los congresos y convenciones. Como coordinadora del volumen he dejado que esas vacilaciones fluyan: aunque tengo mi propio punto de vista al respecto y lo he elaborado en otros trabajos, considero que forman parte del estado de la cuestión. Quizás, uno de los problemas más graves con que se enfrentan los estudiosos de la ciencia ficción escrita en español, además de la inestabilidad misma de su corpus, es la persistencia histórica de la aproximación desde y la rotulación de sus artefactos como fantásticos, en un intento de salvaguardar ciertos artefactos de la ciencia ficción en campos culturales que de otro modo los hubieran condenado al olvido. En cierta medida, esa mirada tiene sus raíces en una acendrada desconfianza hacia formas narrativas que no se ajustan a modelos evidentes de interpretación estética o ideológica. Pero también, esas mezclas y rechazos interpretativos esconden la voluntad de generar una ontología de lo latinoamericano. En este sentido, vale la pena recordar ensayos canónicos sobre lo fantástico, como el de Barrenechea y Speratti-Piñero (1957, seguido casi quince años después por la famosa tipología de Barranechea), que sienta las bases de lectura de lo fantástico como categoría original de producción de la alta modernidad en América Latina y niega toda conexión entre la ciencia ficción y la producción de 
escritores como Lugones, Borges o Bioy Casares. De allí que críticas como Haywood Ferreira debieran insistir en sus trabajos no sólo en la importancia del retroetiquetado de los objetos que deben ser considerados como legítimos en el campo (Haywood Ferrreira), sino también en el trazado de genealogías literarias que fueran consistentes con la forma de producción particular de la ciencia ficción en América Latina. Dentro de esta línea, los trabajos de Abraham y Pestarini así como el mío, intentan un reflexión que pueda dar cuenta de la plasticidad de los objetos que se engloban en el rótulo ciencia ficción: habida cuenta de los cruces genéricos que aparecen en la narrativa de la modalidad en la región, la exégesis la acerca mucho más al Weird y al New Weird que a las viejas formas del pulp americano y los ensayos intentan una reflexión dentro de esta dirección. Es por eso que, como bien señala Abraham, hay una voluntad cada vez más generalizada de hablar de literaturas de lo insólito.

Las problemáticas que atraviesan a la ciencia ficción son complejas y pueden ser estudiadas desde muy diversas perspectivas. Aunque América Latina no se ha caracterizado por generar una ciencia ficción dura en un sentido clásico (es decir, en el sentido en que se lo entiende en el mundo de habla inglesa), la reflexión en torno a las ciencias y a la tecnología ha estado presente desde sus inicios. Si en un primer momento fueron las ciencias médicas y un fuerte biologicismo lo que dominó la reflexión en consonancia con las búsquedas filosóficas del positivismo (tal y como se analiza en el trabajo de Page), la llegada del siglo XX marcaría un abandono del racionalismo en favor de las pseudociencias en el momento en que éstas se convierten objetos de consumo de la cultura de masas al perder su basamento epistemológico y experimental. En el espacio de la ciencia ficción, esos objetos de fantasía se convirtieron en instrumentos de otra cosa, en termómetros de la desazón experimentada por las élites ante la transformación de lo social y de lo político. Los trabajos de Mariano García y de Linck apuntan en esa dirección. Pero la búsqueda de relaciones entre cultura, ciencia y tecnología no se agota en esa reflexión. El surgimiento de nuevas tecnologías así como la emergencia de comunidades en la red ha tenido gran importancia en la aparición de nuevas formas narrativas dentro de la ciencia ficción, así como del desarrollo de estéticas que le son propias. No se trata sólo de nuevas formas de producir narrativas, es decir de nuevos medios que requieren de destrezas específicas para ser decodificados en forma completa (tema que explora Ledesma), sino de poéticas que organizan el mundo en torno a lo tecnológico aún cuando lo tecnológico no necesariamente constituya lo que Darko Suvin definía como novum: se trata de universos que trabajan con una naturalización de lo tecnológico donde el novum ya no es tal ni para el lector ni para el narrador ni para los personajes. El extrañamiento es, como hubieran dicho los surrealistas, el encuentro fortuito de objetos de muy diferentes orígenes en el mismo estrato témporo-espacial. De esta tendencia dan cuenta los análisis de Hernán García, González, L’Hoeste, Pegoraro, y en cierta medida Ginway. Sin embargo, en todos estos ensayos queda claro el fuerte 
componente político, sociológico y epistemológico que recorre los textos analizados. Si la reflexión sobre la relación entre ciencia y cultura tiene un fuerte presentismo en muchos de los textos escogidos por estos investigadores, en sus análisis es fácil entender por qué raramente se ha hablado de hard science fiction en América Latina: todo objeto científico-tecnológico tiene una extraña evanesencia que rápidamente cede lugar a temáticas vinculadas con la formación del imaginario social, político y utópico, con la construcción de subjetividades identitarias de todo tipo (desde el género hasta lo comunitario), o de la otredad como problema ontológico y político, así como una meditación en torno a las consecuencias sociales, biológicas, ambientales y éticas del desarrollo de la tecnología durante el avance del capitalismo tardío. Constituyen ejemplos de lo que Borges describió como "ejercicios de imaginación razonada". Clara muestra de ello son los trabajos de Pelliza sobre la relación entre ciencia ficción $\mathrm{y}$ misticismo, de Blanc-Hoàng sobre las lecturas del colonialismo y del imperialismo en la historieta, y los de Ginway y Sparling sobre sexualidad y feminismo.

La convocatoria original del presente volumen invitaba a presentar trabajos que reflexionaran sobre la ciencia ficción como fenómeno cultural, social y político, enfatizando tanto los aspectos epistemológicos como los conceptuales de la ciencia ficción en América Latina. Así, los trabajos debían enfocar el análisis en temas que incluyeran, pero no se limitaran a las aproximaciones y/o definiciones de género y/o modalidad, la formación del megatexto de la ciencia ficción y las problemáticas del retro-etiquetado, la formulación de una arqueología ideológica, las relaciones estéticas de la ciencia ficción con otros objetos y estéticas del campo cultural, las articulaciones estético-ideológicas de las revistas y fanzines (tanto en su formato en papel como en su formato electrónico), la formación del fandom y la circulación de bienes culturales a nivel continental, etc. Los trabajos seleccionados para este volumen consideran muchas de estas cuestiones desde diversos ángulos y por lo mismo, sus respuestas son también complejas, incluyendo análisis desde la literatura, hasta el cine, pasando por la historieta y la ilustración. En esos estudios puede verse tanto la complejidad de los objetos mismos como de los aparatos teóricos necesarios para desensamblar sus operaciones. Por eso, la organización del volumen intenta proveer un marco conceptual de lecturas que puede seguirse o no. La intención de la propuesta del índice (arbitraria, como toda propuesta) está orientada a facilitar el acceso teórico a colegas que no estén familiarizados con el área. Así, la primera sección, Marcos teóricos: otras herramientas, permite al lector una entrada a los vocabularios y temáticas de la ciencia ficción a partir de las historias nacionales de la modalidad, de una revisión de la teoría sobre ciencia ficción tal y como ha sido leída desde América Latina, y de la emergencia de algunas de las principales problemáticas que la recorren, a saber, las literaturas digitales, el posciberpunk, el neuropunk, la religión, la ucronía, la utopía, la distopía, y la presencia inescapable de Borges. La segunda sección, Entre las literaturas nacionales y la reformulación de un corpus continental, regresa a las cuestiones arqueológicas 
y filogenéticas de la ciencia ficción para trazar sus mapas de lectura (cultural, social, político, estético) a partir de sus conflictivas inserciones en lo local, pero también en sistemas de referencia que no necesariamente aparecen en los discursos hegemónicos de los países de origen de los objetos aquí analizados. La última sección, Otras voces: mujeres, historieta y cine, apunta a incorporar precisamente, esas otras voces y estéticas como parte del continuum de la ciencia ficción con otras prácticas visuales, narrativas y discursias del campo cultural, al mismo tiempo que subraya cómo cuestiones que pueden aparecer como laterales en la narrativa canónica, aquí se ponen en escena de manera frontal. He querido dedicar un espacio a las narradoras de ciencia ficción no solo porque no son la rara avis que muchos críticos creen ver en ellas, sino porque en sus trabajos emergen cuestiones centrales de la modalidad que deben ser estudiadas como piedra basal de muchas narrativas nacionales y no sólo de ciencia ficción. Cerrar con esas voces implica abrir otros debates.

El sistema de apropiaciones de la ciencia ficción, lo que Marcelo Cohen llamaba su amoralidad textual, permite una existencia heterogénea de materiales y de discursos críticos, de estéticas y de perspectivas teóricas sobre cómo decodificarla. Lo que tiene de subversivo y de contestatario la ciencia ficción no es tanto su uso de materiales, sino su mirada a contrapelo, su capacidad para hacer transparente aquello que en el resto del campo cultural se oculta. Si estos trabajos hacen evidente algo es, justamente, que allí donde la capacidad para desarrollar proyectos de todo tipo parece colapsar sobre sí misma, la ciencia ficción ofrece a la cultura, una forma de pensamiento crítico.

Antes de terminar, quisiera agradecer no sólo a quienes han colaborado conmigo tanto en el presente volumen como en el anterior, sino también y muy especialmente a Juan Duchesne Winter por la calurosa acogida que ha brindado al proyecto, a Elizabeth Monasterios por una de las más productivas conversaciones que haya tenido, y a Erika Arredondo por sus pacientes sugerencias. Y a Néstor, por las fotos de la portada, y por todo lo demás.

\section{BiBLIOGRAFÍA CITADA}

Barrenechea, Ana María. "Ensayo de una tipología de la literatura fantástica. A propósito de la literatura hispanoamericana”. Revista Iberoamericana XXXVIII/80 (1972): 391-403.

y Emma S. Speratti-Piñero. La literatura fantástica en Argentina. México: Imprenta Universitaria, 1957.

Bell, Andrea L. y Yolanda Molina-Gavilán, eds. Cosmos Latinos: An Anthology of Science Fiction from Latin America and Spain. Middletown, CT: Wesleyan UP, 2003.

Brown, J. Andrew. Cyborgs in Latin America. Nueva York: Palgrave Macmillan, 2010. 
Cano, Luis C. Intermitente recurrencia: la ciencia ficción y el canon literario hispanoamericano. Buenos Aires: Corregidor, 2006.

Cohen, Marcelo. ¡Realmente fantástico! Y otros ensayos. Buenos Aires: Grupo Editorial Norma, 2003.

Cornejo Córdoba, Antonio. ¿Extranjero en tierra extraña?: el género de la ciencia ficción en América Latina. Sevilla: Universidad de Sevilla, 2011.

Ginway, M. Elizabeth y Andrew Brown, eds. Latin American Science Fiction: Theory and Practice. Nueva York: Palgrave Macmillan, 2012.

Haywood Ferreira, Rachel. The Emergence of Latin American Science Fiction. Middletown, CT: Wesleyan UP, 2011.

Hoeg, Jerry. Science, Technology, and Latin American Narrative in the Twentieth Century and Beyond. Bethlehem, PA: Lehigh UP, 2000.

Mejía, Rivera Orlando. Cronistas del futuro: ensayos sobre escritores de ciencia ficción. Medellín: Universidad de Antioquia, 2012.

Suvin, Darko. Metamorphoses of Science Fiction: On the Poetics and History of a Literary Genre. New Haven: Yale UP, 1980. 
